\title{
Smart Home for the Abled and Disabled Aged Persons in Africa: Design and Development
}

\author{
Okorafor Godfrey Nwaji ${ }^{1}$, Opara Felix Kelechi ${ }^{2}$, Ononiwu Gordon Chigozie ${ }^{2}$, \\ Chukwuchekwa Nkwachukwu ${ }^{2}$ \\ ${ }^{1}$ Computer Science Department, Novena University Ogume, Kwale, Nigeria \\ ${ }^{2}$ Electrical \& Electronics Engineering Department, Federal University of Technology, Owerri, Nigeria
}

\section{Email address:}

nwajigo@novenauniversity.edu.ng (O. G. Nwaji)

\section{To cite this article:}

Okorafor Godfrey Nwaji, Opara Felix Kelechi, Ononiwu Gordon Chigozie, Chukwuchekwa Nkwachukwu. Smart Home for the Abled and Disabled Aged Persons in Africa: Design and Development. Internet of Things and Cloud Computing. Vol. 6, No. 3, 2018, pp. 63-68. doi: $10.11648 /$ j.iotcc. 20180603.12

Received: September 15, 2018; Accepted: September 27, 2018; Published: October 24, 2018

\begin{abstract}
Smart home is an intelligent home network whose services and infrastructure are based information and communication technology. It is an intelligent use of wireless technology for the implementation of automated home electrical/electronic appliances and devices, domestic tasks, and security devices, for the wellbeing of the occupant. However, the development of smart homes has focused mainly on building for the young and able-bodied persons for the purpose of enhancing home comfort, energy saving, and security, without considering the aged and disabled persons in Africa. The Smart Home System were implemented in existing home environments, with the automation focusing on recognition of voice commands and uses low-power RF wireless communication modules along with a microcontroller for message passing. The system consists of voice recognition module for voice input and recognition. The control signal of the recognized command is transmitted to the microcontroller, and the microcontroller uses this signal to control home appliances. The designed system was tested and the result showed that the level of system response is higher in dead home than in a live home, hence, the system performance is affected by the environmental noise and the accents of un-trained aged persons are not supported by it. This system is most suitable for the aged and the disabled persons living alone and is intended to control all lights and electrical appliances inside a house using voice commands. In this work a home automation control system based on voice recognition was designed, implemented and experimental tests done and results were obtained.
\end{abstract}

Keywords: Smart Home, Information and Communication Technology, Wireless Technology, Radio Frequency, Voice Recognition

\section{Introduction}

The notion of smart home was introduced due to the conception of intelligent implementation of consumer electronic devices, electrical equipment, and security devices, automation of domestic tasks, easy communication, and human-friendly control, as well as safety. However, the development of these homes has mainly been focused on building a smart home environment for young and ablebodied persons with the simple purpose of enhancing home comfort, energy saving, and security. However, the need to consider the aged and disabled persons in smart home design have not received adequate considerations in Africa. The aged persons are that percentage population of persons in a given population with ages 65 years and above. The world's aged person's population has grown at an accelerated pace, and 2009 projections gave an estimated 737 million persons were aged 60 years and above, which nearly two thirds of whom lived in developing nations. This number is projected to increase to 2 billion in 2050 [1]. Presently in Africa, the number of elderly persons and persons with physical challenges that require external help to perform their everyday tasks has been on the increase. The decline in mortality rate due to improved health care services and living conditions in Africa has resulted to the increasing population of this aged persons. this continuous rise in the population of the aged persons has resulted to rapid increase in the cost of 
caring for them, hence, worsening the problem of caring for the aged persons due a miss-match on the caring facilities. Also, the number of care-givers has been on the decrease on the other hand, due to high rate of migration of able bodied youths to the cities and developed nations in search of greener pastures. Therefore, the problem of caring for this group of persons has become a serious issue as many of them are always seen clustered at city roundabouts, church gates, event centers begging for arms. Therefore, the level of neglect this group of persons are suffering from the society and the societies' leaders in Africa are shown by the high population of the aged persons involved in arm-begging. It is obvious that the solutions to the problems of this aged persons cannot be solved by increasing the number of caregivers, rather can significantly be reduced by the deployment of various modern assistive technologies, through building of smart homes. Therefore, this proposed project aimed at developing smart home that will meet the increasing needs of this group of persons in their home environments. Hence, the project tends to use the available advanced technological devices to achieve a smart home for the aged persons to meet their special needs.

In order to make the aged persons live smartly and intelligently remote control consumer devices and media sharing in their homes on aided, this work will utilize the recent trends in Information and Communication technology (ICT) that give support to ubiquitous access, and networking of automated electrical gadgets in the home. The use of sensors was deployed to monitor and control the home environment, and thus enabling the occupant of this home access and control their environment through the use of mobile devices.

However, the architectural design of this proposed Home is based on distributed smart multi-agent architectures to overcome the technological challenges such as huge network, central server processing load and embedded resource usage experienced in the currently existing homes. Therefore, this homes for people with special needs was designed to overcome these problems, while their control algorithms were based on commands relevant to the specifics of each user's requirements, because the level of installed technology in this home varies from person to person, depending on the degree of physical impairment, life habits, and desired safety conditions. This smart home system enabled full integration of this group of citizens to the society by providing them the opportunity to show-case their talents in sports, economy building, in exercising their franchise and contributing their own quota to the development of the nations at large.

The main problem this project tends to solve is how to use voice to control home appliances to the convenience of the aged persons living alone in their homes. Therefore, the project tends to address this problem through the design and development of prototype of a smart home that the aged persons in Nigeria will use voice to control the home appliances, considering their level of literacy and technological knowhow adaptability. The main objective of this research is to design and develop a smart home for the aged persons, in a Nigerian community based setting. This home network improves the Quality of Life (QoL) of the aged persons by enabling them perform their daily life activities and access the basic facilities of life such as educational facilities, medical treatments, participate in governance, and so on. In other words, it increases the quality of life, life expectancy, and self-esteem of the aged persons.

\section{Review of Related Works}

The high population of the aged persons involved in armbegging, showed the level of neglect this group of persons are suffering from the society and the societies' leaders. According to the Office for National Statistics, the major contributor to the rising numbers of the ageing population is an overall improvement in medical treatment, housing and living standards, and nutrition [2]. However, the continuous rise in the population of the aged persons has resulted to rapid increase in the cost of caring, hence, worsening the problem of caring for the aged persons due a miss-match on the caring facilities. Although, few of these persons can be found in their family homes, nursing homes, hospitals, and so on, the costs of their maintenance in these places are very expensive. Hence, they are not adequately taken care of either by their families or care-givers, and their talents are allowed to waste just because they are old. In finding solution to the problem, the authors in [3], studied the merger between gerontology and technology known as Gerontechnology, which is the process of using technological advancements to improve the health, control mobility, communication, and control of environment of the aged persons.

The emergence of smart home systems has become popular in the world nowadays in assisting the end users specifically the disabled and the aged persons, but due to their complexity and cost it is not always deployed. Its main benefits range from increased comfort and greater safety and security, to a more rational use of energy and other resources, allowing for significant savings. It also offers powerful means for helping and supporting the special needs of the aged persons with disabilities. Maqsood in [4] implemented techniques and provided a viable solution to achieve smart home system which constitutes wireless Bluetooth control via Android app development for in-home control and Global System for Mobile Communication (GSM) technology for mobile control using Arduino. The authors in [5] implemented speech recognition-based remote control of home devices, the authors in [6] designed a system that was able to monitor and control lights, room temperature, alarms and other household appliances. The hardware part mainly consists of a digital computer, an Arduino Uno board, Light Detecting Resistors, Temperature sensor (LM35), LPG and Smoke sensor (MQ2), Temperature and Humidity sensor (DHT11), Webcam, DC Motor. The authors in [7] showed that smart home system allows the control of home appliances like door, light, fan, oven and so on, and their 
design has emergency system and home security. their system allows the occupants more control of their home and it facilitates through reduction of human efforts and time saving. The authors in [8] showed how to use Android based control system to control the security of home entrance and also the car door lock. The Authors, B. Murali Krishna and co, presented a home automation system using Android Smart Phone to control an application in their design. They connected Bluetooth module to FPGA board to control the home appliances, [9]. The authors [10] in their design, implemented a remote access home automation controller through and its good features, using GSM network for this purpose. The design and implementation of a low cost, tangible, flexible based device automation system depending on secure cell phone was done in [11].

Lia Kamelia, and co, proposed and produced a prototyped system called door locks automation system using Bluetoothbased Android Smartphone [12]. D. Jaya Sree and M. Jhansi Lakshmi presented the design of Home Automation System that replaced the existing electrical switches which status is synchronized in all the control system with low voltage activating method that provides more safety control [13]. Voice controlled home automation system that uses an Arduino Uno microcontroller with smart phones for the operation control was done in [14]. Here, different design and home appliances such as different electric applications controlled using Arduino UNO Microcontroller Based Home Automation System are presented. The system performs its function by controlling the DC motor speed and its direction, bulb, fan and heater using a smart phone application with Bluetooth wireless technology.

Voice control method offers a more user interactive approach in delivering control commands [15], By applying speech recognition system, a system can be developed to help user control devices remotely. Voice control system for ZigBee based home automation has been introduced in journal of "ZigBee based voice Controlled Wireless Smart Home System". Speaker independent automatic speech recognition technique has been used. In this system Zig Bee network receives voice command as input to an ARM9 controller, which converts the data into a required format to be used in the microcontroller. Finally, the system generates some control characters to switch ON/OFF the home appliances [16].

There are two types of speech recognition system. They are speaker-dependent and speaker-independent system. Speaker-dependent system is designed for a specific speaker that works by learning the unique characteristics of a single person's voice [17]. It is also known as voice recognition. New users must first "train" the software by speaking to it, so the computer will have analyzed how the person talks. This system is useful as the security system. Speaker-independent systems on the other hand, require no training phase with data of users, and are desirable to many applications where training is difficult to conduct [18].

Arduino UNO is a multi-purpose microcontroller board based on the ATmega328P. It has 14 digital input/output pins and 6 analog inputs. Each of the 14 digital pins on the Uno can be used as an input or output. An Arduino Uno board can either be powered via USB connection or with an external power supply (AC-to-DC adapter or battery). Leads from a battery can also be inserted in the Gnd and Vin pin headers of the power connector. The board can operate on an external supply of 6 to 20 volts [19]. Arduino Uno can communicate with other devices such as a computer, another Arduino board, or any other types of microcontrollers. Its software serial library allows serial communication on any of the Uno's digital pins [20]. In the journal of title "Improved Authentication Using Arduino Based Voice \& Iris Recognition Technology", a voice recognition system is proposed to build as security function. The Arduino board as important role integrate with EasyVR Shield [21]. The proposed system is using speaker-dependent system to train the password command. In this project also using the password command rolled as the security of the system. Therefore, the usage of both boards can be used to develop a speech recognition system.

The wheelchair project brings together researches into autonomous wheelchairs as well as from the area of dialogue management. Wheelchairs are rich and promising platform for intelligent agents and are being explored by many groups as a way to assist the aged individuals. Some of the significant researches that has been conducted in this area includes [22] which addresses the application of techniques from robots to autonomous wheelchair navigation. Though, a wheelchair can be treated as a robot, it is necessary to take the human into account. Many assistive Internet based technologies exist which support and encourage the use of technology by older people. Race Online, an initiative aimed at making the UK the first nation in the world where everyone can use the Internet [23]

\section{Methodology}

Recently, different kinds of researches to develop technologies that can significantly offset the decline in health and self-care abilities and enable aged persons with or without disabilities to continue to live alone in a home. The methods used in achieving this home involved the hardware and the software design and development. In the hardware development process, the system modular block diagram, and the system schematic diagram were used. The system block diagram showed the system`s module interactions and operations together with the component units on a much detailed description, and is related to the system conceptual diagram. However, the system schematic diagram displays the low-level description of the design, with complete detailed presentation of components and their connections. However, the flowchart used in the software design and development operations presented the step-by-step procedures for the implementation of software programs used in system controller and Personal Computer. 


\section{The Proposed Smart Home Development}

Smart Home (SH) evolved from automated home whose building block is made-up of the elements such as HVAC electrical, Light, security systems, and the emerged home is a structure that contains the basic $\mathrm{SH}$ functions that are completely dynamic with many interactions.

The components in smart home network architecture are general controlled by a Central Control Unit (CCU) that is the users service provider. The CCU contain all the home system operating protocols, the users control all the appliances and components via the CCU. Figure 1 shows the smart home architectural setup for the central control unit for the control of the home appliances. The proposed system is composed of two major units; the remote system transmitter controller unit that comprises of the input recognition devices modules, and the remote system receiver controller unit that is made up of the electrical and electromechanical units, and the emergency call units.

The CCU Block is responsible for recognizing the voice commands, evaluating decisions and generating control signals. Every time a voice command was received through a microphone, it is evaluated in the voice recognition unit. If a voice command was successfully recognized, decisions are made through the central control unit, which then generates control signals which are sent wirelessly to the remote receiver for the control of the home appliances thorough the $\mathrm{I} / \mathrm{O}$ pins of the microcontroller. The central control also sends emergency control signals to the emergency unit when a push button is depressed.

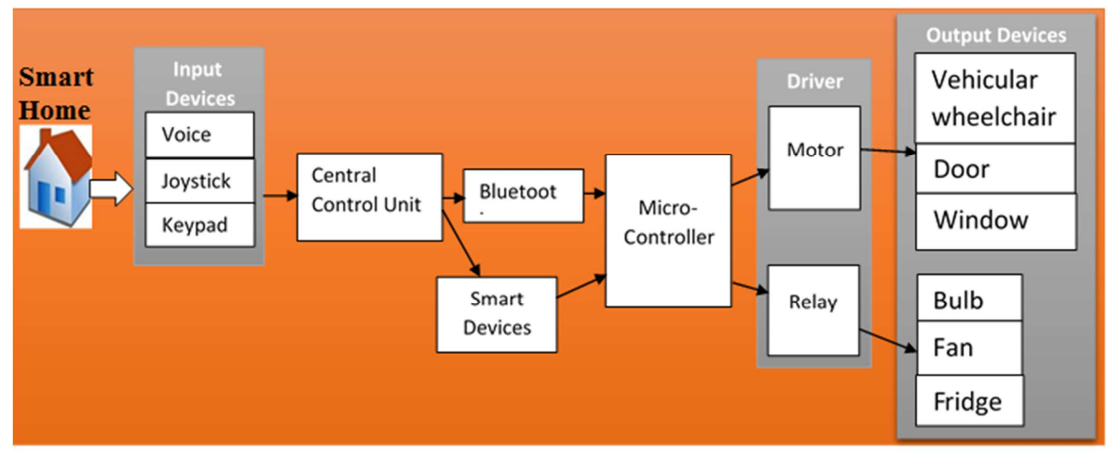

Figure 1. The Smart Home Architecture.

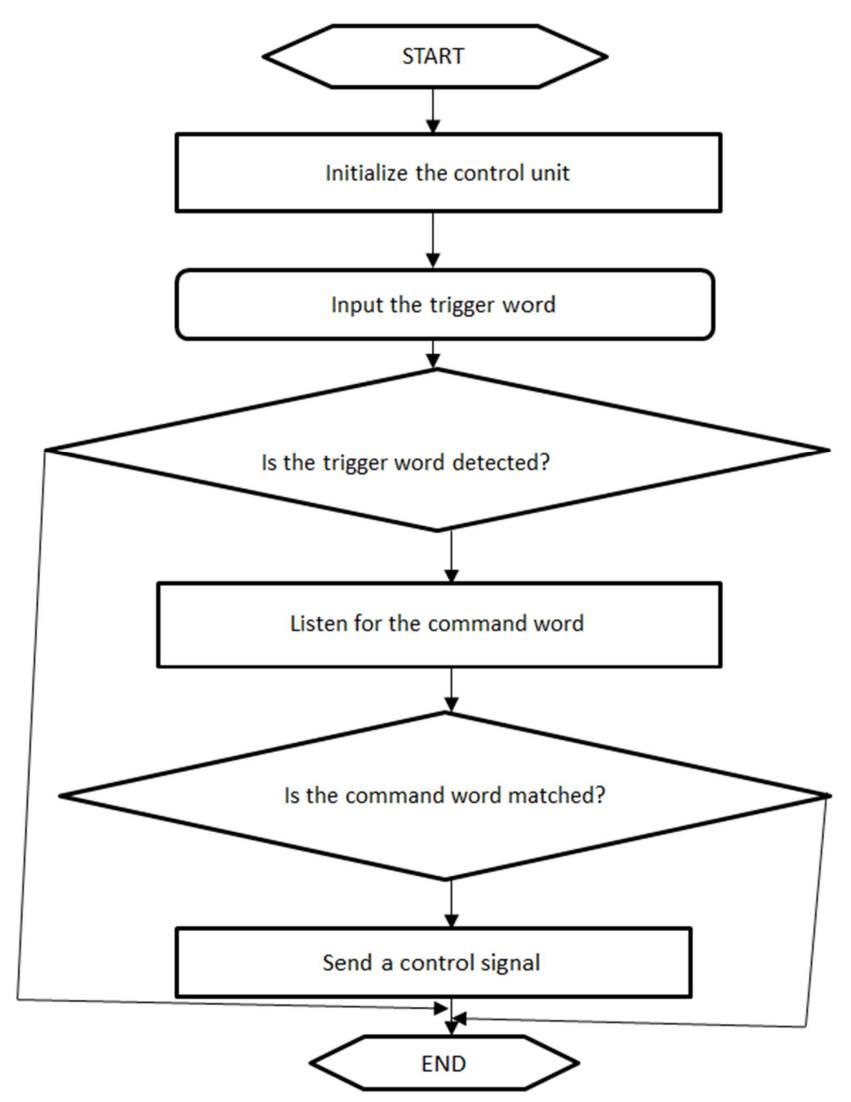

Figure 2. Control Algorithm
The control unit which is a PC-interface that consist of microcontroller block and PC software of the central control serves as a communication interface between the user and the smart home assistive facilities. If control signals are generated by the user, the $\mathrm{CU}$ informs the user about the updates of these signals through open/close of the door/window, or receive emergency attention, and so on, the microcontroller block receives control signals coming from the controller unit under the main-controller unit. If the control signal was successfully recognized, the microcontroller block sends output signals, which open/close the door/window, and so on, or make emergency call. The control algorithm is illustrated in the diagram of figure 2 below.

\section{Result and Discussion}

This section presents the interpretation of the results obtained during the system voice training tests conducted. The voice commands of the aged beneficiaries were encoded into the system, through the process known as system training, and the tests to determine the distance of the voice input device effectiveness from the user (input sensitivity test), find the level of systems response and accuracy were carried out. The system performance was evaluated via calculating the average response time, the percentage error of the system, and the probability to find whether the command 
transmitted is the command executed, within the response time were determined. These tests were done in an empty home, while, a live home has the same content as the empty home, but with television on, people talking with background music coming from a stereo, curtains were open and external noise outside home were experienced during the test period.

The results show that the system is very much responsive in an empty home than in a live home, also, the data collected showed that the sensitivity of the input device to voice command is highly responsive and very effective at close range.

The trial percentage error of each trial from each tester is given by equation 1 :

$$
\% \text { Error }=\left[\frac{\mathrm{E}-\mathrm{V}}{\mathrm{E}}\right] \times 100
$$

Where, $\mathrm{E}$ is the accepted value, in this case it is 19 since there are 19 commands to be considered while $\mathrm{V}$ is the experimental value which is the result from the test conducted. It is the number of commands where the system responded correctly.

The average error per tester was calculated using the equation 2:

$$
\frac{E_{1}+E_{2}+E_{3}+E_{4}+E_{5}+E_{6}}{6}
$$

Where, $E_{1}, E_{2}, E_{3}, E_{4}, E_{5}$ and $E_{6}$ are percent errors obtained from equation 1 .

The effectiveness of the system for an empty and a live environment were respectively calculated using equation 3 :

$$
100-\left[\frac{\text { Ave }_{1}+\text { Ave }_{2}+\cdots+\text { Ave }_{6}}{6}\right]
$$

The results of the various percent error calculations were

\begin{tabular}{|c|c|c|c|c|c|c|}
\hline \multirow{2}{*}{ TESTERS } & \multicolumn{3}{|c|}{ ЕМРТY НОМЕ } & \multicolumn{3}{|c|}{ LIVE HOME } \\
\hline & \multicolumn{2}{|c|}{ \% ERROR } & AVERAGE \%ERROR & \multicolumn{2}{|c|}{$\%$ ERROR } & AVERAGE \% ERROR \\
\hline \multirow{6}{*}{ Nwabi } & $\mathrm{T}_{1}$ & $0 \%$ & \multirow{6}{*}{$1.04 \%$} & $\mathrm{~T}_{1}$ & $33.25 \%$ & \multirow{6}{*}{$33.41 \%$} \\
\hline & $\mathrm{T}_{2}$ & $0 \%$ & & $\mathrm{~T}_{2}$ & $35.75 \%$ & \\
\hline & $\mathrm{T}_{3}$ & $0 \%$ & & $\mathrm{~T}_{3}$ & $30.22 \%$ & \\
\hline & $\mathrm{T}_{4}$ & $0 \%$ & & $\mathrm{~T}_{4}$ & $34.25 \%$ & \\
\hline & $\mathrm{T}_{5}$ & $0 \%$ & & $\mathrm{~T}_{5}$ & $36.22 \%$ & \\
\hline & $\mathrm{T}_{6}$ & $6.25 \%$ & & $\mathrm{~T}_{6}$ & $30.75 \%$ & \\
\hline \multirow{6}{*}{ Mgborie } & $\mathrm{T}_{1}$ & $0 \%$ & \multirow{6}{*}{$2.29 \%$} & $\mathrm{~T}_{1}$ & $49.25 \%$ & \multirow{6}{*}{48.67} \\
\hline & $\mathrm{T}_{2}$ & $6.25 \%$ & & $\mathrm{~T}_{2}$ & $48.27 \%$ & \\
\hline & $\mathrm{T}_{3}$ & $6.25 \%$ & & $\mathrm{~T}_{3}$ & $46.25 \%$ & \\
\hline & $\mathrm{T}_{4}$ & $1.23 \%$ & & $\mathrm{~T}_{4}$ & $50.23 \%$ & \\
\hline & $\mathrm{T}_{5}$ & $0 \%$ & & $\mathrm{~T}_{5}$ & $49.75 \%$ & \\
\hline & $\mathrm{T}_{6}$ & $0 \%$ & & $\mathrm{~T}_{6}$ & $48.25 \%$ & \\
\hline \multicolumn{3}{|c|}{ TOTAL EFFECTIVENESS } & $98.34 \%$ & & & $58.96 \%$ \\
\hline
\end{tabular}
tabulated in table 1 .

Table 1. Overall Effectiveness of the Designed System.

The table 1 showed the overall percentage error results of the testing both on an empty and a live room. Here, almost all trials in an empty room achieved $0 \%$ error and it shows that even at average it still has a lower percent error. While, when the area of testing is in a live room, higher percent error occurred, because of the noise surrounding the device thus, the average percent error for the live room is larger.

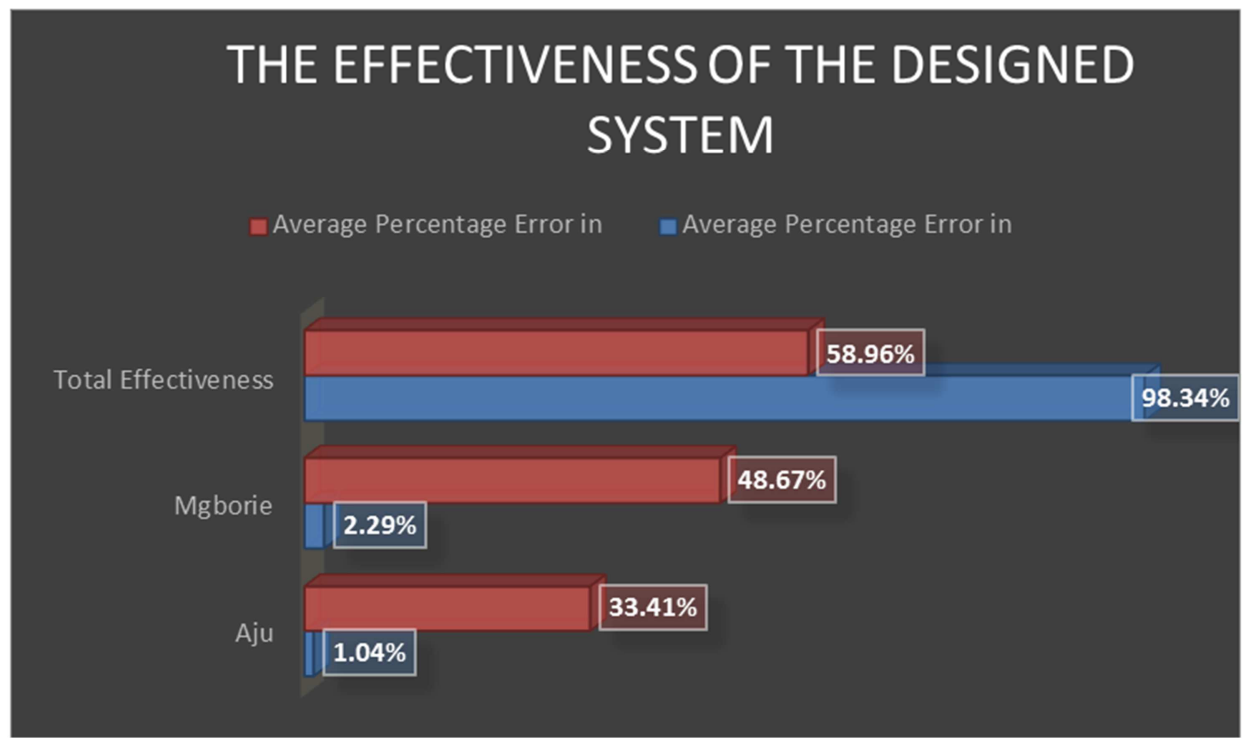

Figure 3. An Empty Home and a Live Home Comparisons of the test result. 
Overall it can be seen from figure 3 that the design is much more effective in an empty room with $98.34 \%$, while in a live room it is only $58.96 \%$. Hence, based on the results, it can be seen that the system works better on a less noisy area.

\section{Conclusion}

The system designed in-depth innovation in smart home development and services, because, it had promoted hightechnology kind of a smart home which the aged persons have find to be more convenient. Based on the objectives of the design, several conclusions can be made: The system design allows the user to turn on \& off: lights, fan, and refrigerator through voice recognition. The system design also allows the user to use voice commands to navigate the motorized wheelchair, open \& close doors and windows, and make emergency calls. However, this smart home system functionality and usability can further by making the system to support all foreign accents and languages, since most of the occupants in a smart home are mostly fluent with their local languages.

\section{References}

[1] National institutes of health, U.S., (2008). "Why population aging matters - A global perspective", National Institute on aging, Department of health and Human Services.

[2] Race Online, (2011). URL http://raceonline2012.org/.

[3] Graafmans J., Taipale V., and Charness N., (1997) "Gerontechnology: A Sustainable Investment of the Future". Amsterdam, the Netherlands: IOS.

[4] Maqsood J, (2014) "Artificial Intelligence, Modelling and Simulation (AIMS)", 2014 2nd International Conference, Madrid, pp. 109-114.

[5] Cubukcu, A.; Kuncan, M.; Kaplan, K.; Metin Ertunc, H., (2015) "Development of a voice-controlled home automation using Zigbee module", Signal Processing and Communications Applications Conference (SIU), Malatya, pp. 1801-1804, 16-19.

[6] Adriansyah, A.; Dani, A. W., (2014) "Design of Small Smart Home system based on Arduino", Electrical Power, Electronics, Communications, Controls and Informatics Seminar (EECCIS), Malang, pp. 121-125, 27-28

[7] D. Naresh, B. Chakradhar, S. Krishnaveni, (2013) "Bluetooth Based Home Automatic and Security System using ARM9", International Journal of Engineering Trend and Technology (IJETT), Vol. 4 Issue 9.

[8] Satish Palaniappan, Naveen Hariharan, Naren $T$ Kesh, VidhyalakshimiS, Angel Deborah S, (2015) "Home Automation Systems - A Study "International Journal of Computer Applications Vol. 116, No. 11.
[9] B. Muralikrishna, V. Narasimaha Nayak, K. Ravi Kishore Redd B. Rakesh, P. Manoj Kumar, N. Sandhya, (2015) "Bluetooth Based Wireless Home Automation System using FPGA", Journal of Theoretical and Applied Information Technology, Vol. 77, No. 3.

[10] Simpson, R. (2005), "Smart wheelchairs: a literature review". Journal of Rehabilitation Research \& Development, 42(4), 423-438.

[11] O. Prabhakar, \& N. Sahu (2013). A Survey On: Voice Command Recognition Technique. International Journal of Advanced Research in, Vol. 3, No. 5, pp. 576-585.

[12] Lia Kamelia, Alfin Noorhassan S. R., Mada Sanjaya and W. S., Edi Mulyana, (2014) "Door-Automation System using Bluetooth-Based Android for Mobile Phone", ARPN Journal of Engineering and Applied Sciences, Vol. 9, No. 10.

[13] D. Jaya Sree and M. Jhansi Lakshmi, (2014), "Android Mobile Based Home Automation using Bluetooth", International Journal of Advanced Research in Computer Engineering \& Technology (IJARCET) Vol. 3 No. 9.

[14] T. Obaid, H. Rashed, A. A. El Nour, M. Rehan, M. M. Saleh, and M. Tarique (2014), "Zig Bee Based Voice Controlled Wireless Smart Home System", In:International Journal of Wireless \& Mobile Network (IJWN) Vol. 6, No. 1.

[15] L. Ningqing, Y. Haiyang and G. Chunmeng, (2013), "Design and implementation of a smart home control system,". In: Proc. - $3^{\text {rd }}$ Int. Conf. Instrum. Meas. Comput. Commun. Control. IMCCC 2013, pp. 1535-1538.

[16] Taha, T., Miro, J., \& Dissanayake, G. (2008), "POMDP-based long-term user intention prediction for wheelchair navigation". International Conference on Robotics and Autonomation (pp. 39203925).

[17] Office for National Statistics (2011), "Statistical bulletin: older people's day". URL http://www.statistics.gov.uk/.

[18] McLoughlin I. (2009). Applied Speech and Audio Processing with MATLAB examples", Cambridge University Press.

[19] A. A. Galadima (2014). "Arduino as a learning tool," In: $11^{\text {th }}$ Int. Conf. Electron. Comput. Comput., pp. 1-4.

[20] Arduino (2014). "Introduction: Arduino Uno Overview." Retrieved from arduino.cc/en/Main/ArduinoBoard Uno.

[21] Sadeque Reza Khan and Farzana Sultana Dristy, (2015) "Android Based Security and Home Automation System", International Journal of Ambient Systems and Applications (IJASA) Vol. 3, No. 1.

[22] Sonali Sen, Shamik Chakrabarty, Raghav Toshniwal, Ankit Bhaumik, (2015) "Design of an Intelligent Voice Controlled Home Automation System", International Journal of Computer Applications, Vol. 121, No. 15.

[23] Rani, M. U., Goutham, J., \& Parthiban, M. (2014). "Improved Authentication Using Arduino Based Voice and Iris Recognition Technology", pp. 2319-2322. 